gastrorrhaphy, and the latter by pyloroplasty or by gastroenterostomy.

InTESTINAL ObSTRUCTION.

I hold that every case of intestinal obstruction is a case for consultation, and should be seen at an early stage by a surgeon, inot necessarily for operation, but that he may be prepared to interfere as soon as ordinary remedies have failed, and before the system has become poisoned by the fermenting contents of the gut above the seat of obstruction; moreover, in an early stage, the diagnosis of the nature and seat of the obstruction can be more easily made out, and, if the obstruction be a mechanical one, such as an internal hernia, a band or a volvulus, the less delay in operating the better for the patient, for nothing short of operation is likely to afford any relief. How frequently is the surgeon called in to relieve obstruction when the patient is moribund from septicæmia, and when all that he can do is to bring up a loop of bowel and drain it, the result being some slight relief, but in a great number of cases only for a short period. Then, unfortunately, surgery is blamed for the death, whereas the blame should be on the delay in applying surgical treatment. I have seen some of the most simple operations, such as the simple division of a band or the reduction of an internal hernia, to fail, not because of the technique or because of the failure to relieve the obstruction, but because the distended bowel had become paralysed and the mucous membrane necrosed before relief had been sought by the only means possible. This was very well demonstrated by Professor Kocher in a paper he gave before the British Medical Association in Edinburgh, on the Causes of Death in Acute Intestinal Obstruction, in which he showed photographs of the ulcerated and gangrenous mucous membrane in the gut above the seat of obstruction.

The dangers of delay in this class of cases could be illustrated by very many examples, but as we doubtless all know of cases in point I will not take up more of your time, but would simply urge that we should strive to avoid these dans er 3 by an early surgical consultation, and, if needful, operation.

\section{Ovarian Tumours.}

I have operated some hundreds of times for large ovarian tumours, and the question has often crossed my mind during the operation, Why should these cases have been allowed to go on so long before being submitted to operation, when by bimanual examination they can be recognised in their infancy and removed with almost absolute certainty of recovery before any complications have supervened? Sometimes, of course, it is owing to the patient having failed to seek advice, but I know that in many cases it is due to that laissez faire policy of not interfering until the tumour is producing distress, which frequently means waiting until some complications have supervened demanding early operation, when the dangers of ovariotomy are decidedly increased; in fact, in this case we may put down the dangers of delay as 4 or 5 per cent. as compared with the almost complete absence of danger in early operation, to say nothing of all the discomfort and inconveniences which have to be borne.

To give examples of suppurating cysts, cysts with twisted pedicles, cysts with numerous and firm adhesions, general peritonitis owing to ruptured cysts and other complications, all of which might be avoided by early operation, is unnecessary, and I think everyone will agree that here delay is most undesirable.

\section{UTERINe TUMOURs.}

Here we are entering on more debatable ground, but I think it is becoming more generally recognised that myoma uteri is not the harmless growth that it was once considered to be ; for though at first it is usually benign, it not infrequently undergoes sarcomatous or carcinomatous degeneration.

It is usually thought that these tumours disappear at the menopause, and that therefore waiting may be counselled; but how often are we disappointed to find that the climacteric brings no amelioration, but that the growth and hæmorrhage persist long after a change has been expected. Moreover, in many of the cases where such amelioration does occur, how often does it come to a patient so worn down by hæmorrhage and pain that she remains a permanent invalid for the rest of her existence.

Apart from myomata breaking down and sloughing, and so giving rise to septic troubles, other complications arise from pressure on nerves, ureters, kidneys, and rectum, leading to complications of various kinds; so that the simple myoma is by no means the harmless disease that it was conveniently considered when its surgical treatment was so unsatisfactory and fraught with so much danger.

The mortality from removal of the appendages, myomectomy or hysterectomy, has been reduced to such a low figure that we may now venture to consider the question as to whether every myoma should not be treated like an ovarian cyst, and operated on at an early stage. My own feeling is, if causing no trouble, we may be content to wait; but as soon as it causes inconvenience or tends to grow, especially if in a young person or if in a woman who has to work for her living, it should be operated on without waiting for all the dangers and inconveniences which we know that delay will entail.

REFERENCE.

1 Plil. Med. Journ., June 14 th, 1898.

\section{THE PROGNOSIS AND TREATMENT OF ACUTE INTUSSUSCEPTION.*}

By GEORGE HEATON, M.A., M.B.Oxon., F.R.C.S., Surgeon to the Birmingham General Hospital.

THE frequency of intussusception as a cause of acute obstruction of the bowels and death was, until quite recent years, not sufficiently recognised, and in my own student days we were accustomed to look upon the disease as one of extreme rarity. The explanation of this probably lies in the fact that as the trouble is particularly common in young children, and in them is apt to terminate fatally very quickly, its presence was in many cases overlooked.

Leichtenstein's statistics would seem to show that it forms quite 40 per cent. of all the cases of acute intestinal obstruction, and two or three such cases are seen almost every year at most of our large general and children's hospitals.

\section{Diagnosis.}

The diagnosis of ir.tussusception is not, as a rule, a matter of any great ditticulty unless the main symptoms be masked or otherwise obscure. Fifty per cent. of the cases occur, according to Treves, in children under 10 years of age, and it seems to be slightly commoner among boys than girls. The main symptoms are a sudden onset of abdominal trouble with vomiting, the presence of blood and mucus in the rectum, tenesmus, and the presence of an abdominal tumour.

I. Of all the classical symptoms, the presence of bloody mucus in the rectum or its passage per anum is of such frequent occurrence as to be almost pathognomonic of the disease. It is present in more than 80 per cent., and its presence in a young child "who has been taken suddenly ill with acute abdominal trouble should make us strongly suspect an intussusception.

2. The onset of the illness is usually sudden, and is often attended with collapse. The pain, as is usual in intestinal obstruction, is generally referred to the umbilicus, and is colicky in character. Actual vomiting is a very variable symptom, and may be absent from first to last. In about a quarter of the cases it is persistent, and becomes fæculent. It is comnionest-as one might expect-in intussusceptions occurring in the small intestine. It generally becomes more persistent towards the fatal termination of a case, and is then probably due to the peritonitis which has supervened.

Straining or tenesmus was a marked symptom in three of my cases, but it not so constant a symptom as either vomiting or the passage of blood. It would seem to be most marked in intussusceptions of the large intestine, or when the intussusception, beginning in the small intestine, has reached the rectum.

The presence of a sausage-shaped tumour in addition to the symptoms enumerated above would make the diagnosis almost a matter of certainty. But in 50 per cent. of the cases no such tumour can be made out. The tumour is somewhat elongated, often easily movable, and owing to the fact that intussusceptions most frequently commence at the ileo-cæcal * Read be: ore a meeting of the Midland Medical Society, February isth, 
valve, it is generally first to be felt on the right side of the abdomen, and then passes across the umbilical region towards the left hypochondrium, as the intussusception passes down the colon.

I do not think quite sufficient stress is generally laid on the suddenness of the onset and the colicky nature of the pain in these cases. These have been marked symptoms in the cases I have seen.

The apex of the intussusception in a certain number of cases may protrude from the anus or be felt per rectum. I have not referred to it as a symptom, for though its presence makes the diagnosis certain, it is a sign of ill omen and should never be waited for. In most of the cases in which it is present the intussusception is already irreducible and the great majority of such cases prove fatal.

Prognosis.

In discussing the prognosis of intussusception it must be remembered at the outset that a number of cases have been recorded of undoubted recovery after gangrene and spontaneous separation of the gangrenous bowel without any other treatment than careful dieting. Such an event, however, is one of extreme rarity, and the mortality of cases where nothing more is done than a mere passive expectant treatment is as high as 98.8 per cent. Statistics and mortality tables, compiled from the published records of cases, are frequently apt to give too rosy a view of the results of any particular form of treatment owing to the inclination which naturally exists on the part of all to publish successes rather than failures. But even such statistics show the mortality of the disease under all forms of treatment up to within a few years ago was as high as 70 or even 80 per cent.

I have adopted a different method in attempting to arrive at a true mortality of the various measures employed for the relief of the disease. I have collected from the published hospital statistics of a few London and provincial hospitals during the years 1888-1898 records of all the cases of intussusception admitted into those institutions ; and endeavoured from them to draw some conclusions.

I have in this way collecied records of 104 cases of intussusception, and though the details in many of the cases have been meagre and lacking in important particulars, yet the numbers are sufficient to justify our arriving at certain conclusions.

I have in this connection to acknowledge my indebtedness to a valuable paper by Mr. McAdam Eccles in St. Bartholomew's Hospital Reports for 1897 , and to my colleagues at the General Hospital for permission to make use of their cases.

Of the total 104 cases, 38 recovered, whilst 66 died. This gives a mortality of 63.4 per cent. It is, indeed, a high one, and in reality should in all probability be even higher, for several doubtful cases have been included which recovered.

On the other hand it includes a large number of cases in which no active treatment whatever was adopted, or where, inflation having proved unsuccessful, no further operative treatment was deemed advisable. It also includes a number of cases in which the patients were moribund when admitted into hospital, and only the post-mortem examination revealed the true cause of death.

The abdomen was opened in 55 cases out of the ro4, generally after failure by injection or inflation to reduce the intussusception.

Of these 55 cases, all details are wanting in 8 of them, so they have been excluded. The remaining 47 can conveniently be divided into two groups :

I. Those in which the intussusception was capable of being reduced.

2. Those in which it was irreducible or gangrenous.

Class $A$.-Reducible : 23 cases-8 deaths, 15 recoveries, giving a mortality of 34.8 per cent

Class B.-Irreducible or gangrenous : 24 cases-22 deaths, 2 recoveries mortality 9r.7 per cent.

Some valuable statistics have been published by C. L. Gibson, of New York, in the Medical Record for July I7th, 1897 , based upon the published reports of 239 cases. They are of course open to the objection I before mentioned, that published cases are apt to be records of successes rather than of failures. He gives somewhat similar figures to minenamely, a mortality of 38 per cent. for the reducible cases and of 82 per cent. for the irreducible cases when submitted to abdominal section.
The causes of death and the ages of the patients in the unsuccessful reducible cases are of interest. The ages of the fatal 8 cases were: $6,10,6,5,8,4,13,5$ months, or an average age of 7 months. The average age of the successful 15 cases was 3 years ro months. This shows how extremely fatal the disease is in children under I year.

The cause of the fatal issue in the reducible cases was usually shock or exhaustion. In the irreducible cases the only two successful ones were two in which excision of the entire intussusception was performed. The deaths were due generally to shock or peritonitis.

I have been unable to find out in a sufficient number of cases the duration of the patient's illness before submitted to operation to justify drawing any trustworthy conclusions. But Gibson, in his table of 149 cases operated upon, shows that the percentage of cases in which the intestine was irreducible varied directly with the number of days of illness.

$$
\text { First day of illness. Percentage of irreducible cases , , , }
$$
Third Fourth

As the mortality is 34.8 in the one and $\ddot{91.7}$ in the other the importance of early operation if it is to be successful is evident.

Treatment

Inflation of the bowel by air or liquid was for many years the only active form of treatment ever adopted, and even now is usually given; a trial before abdominal section.

It must be remembered, however, in estimating its efficacy and in comparing it with treatment by abdominal section, that in the worst cases, where the intestine? is evidently gangrenous or hopelessly irreducible it, is not usually tried, and that the majority of cases in which it fails to reduce the intussusception are afterwards given the slender chance afforded by abdominal section. To form thus any just idea of its worth we must include amongst the failures of this method all those cases afterwards operated upon whether successfully or not.

Out of the 104 cases in my series 63 were given the chance of inflation. Of these 63 cases it was successful in 15 . In the remaining 48 cases the intussusception was unaffected or quickly returned. These numbers give a percentage of 23.9 successes and 76.I failures.

These figures would show, that even among the reducible intussusceptions inflation is not such a successful mode of treatment as abdominal section.

The figures given above show a high mortality for the disease however it be treated; but there is this encouraging fact-the mortality seems to decrease every year. In drawing up these figures in the first few years of the period 1888-98 one came across scarcely a single record of recovery, but in the later years the statistics were much better.

At the General Hospital during the last two years we have had 9 cases admitted, 2 of which were moribund on admission, zet we have had 4 recoveries.

The future success or failure of our treatment of intussusception lies with the physician and general practitioner rather than with the surgeon. Eariy recognition followed by prompt operation will in the future save the majority of these patients, but the rescue of a late case with gangrenous intestine as yet remains an almost hopeless task.

If treatment is to be of any avail in intussusception when once the diagnosis has been made there should be no delay, no waiting twenty-four hours in hope the symptoms will abate. The patient may be given a small morphine hypodermic to ease his pain and check the peristaltic movements of the intestines, while preparations are at once made for active measures.

Inversion of the patient and massage of the intestines through the abdominal walls are credited as having been the successful means of reducing an intussusception, but few if any surgeons would advocate or even countenance such barbarous methods now. The choice of procedure lies between immediate abdominal section and manual reduction of the telescoped bowel, or an attempt to do this by inflating the lower bowel with air or injecting it with fluid.

The advantages claimed for the method of injection are that a fairly large number of successes have been recorded where it has been tried; that the extra shock inseparable from an abdominal section is avoided, and that in case of failureit is always open to proceed to abdominal section. The distension of the 
bowel should be made with liquid, and not air, and the fluid should be forced in by gentle hydrostatic pressure, and not by means of any form of syringe. By using a low pressure (not more than 2 feet of water) and allowing it to slowly enter the rectum, the risk of rupturing the coats of the bowel is reduced.

The great disadvantages, to my mind, of any treatment by large enemata, are :

I. First of all, the immediate risk of over-distension and rupture of the bowel by the distending force. Several surgeons have had the courage and candour to put on record such cases; and at the post-mortem examinations of several fatal cases after inflation the bowel has been found lacerated.

2. Secondly, that it is quite impossible through the unbroken abdominal wall to determine positively that an intussusception has been completely reduced. When the symptoms continue after apparent reduction by enemata it is found at the subsequent operation, or at the post-mortem examination, that the reduction has not been complete, or, as the advocates of inflation generally put it, that the intussusception has recurred. In point of fact, it is always a case of incomplete reduction. When operating upon recent intussusception it is as a rule quite easy to reduce the major part of the imprisoned bowel. It is the last half-inch or inch which creates the difficulty; and it is precisely this same last halfinch which is apt to remain unreduced by inflation.

3. But lastly, the greatest drawback to inflation is that if symptoms continue in spite of apparent reduction, valuable time has been lost, and the golden opportunity of reduction by any means has gone by.

For these reasons I would limit treatment by inflation to cases of intussusception in young infants of under 6 months, who bave only been ill a few hours, and in whom an abdominal tumour is well marked, and would be prepared to at once do laparotomy if the tumour did not entirely disappear.

Abdominal Section.

Abdominal section is the treatment par excellence for intussusception, and the success or non-success of this method will depend in the future more upon early diagnosis on the part of the attending physician than upon anything else.

The death-roll of intussusception up to within the last year or two has been a standing opprobrium to our art, and we may as well openly pose as fatalists as stand by with folded hands, as has been the custom too often in the past, and wait for the $r$ in 100 chance of spontaneous cure.

Yet in spite of this we are told, in one of the most recent American textbooks, in cases of acute obstruction from intussusception "if these means (inflation, manipulation, etc.) do not prove successful by the third day surgical measures should be resorted to." By the third day 38 per cent. of the intussusceptions will have become irreducible, and their cure a desperate hope.

The operation itself may prove a very simple one, or in a complicated irreducible case may call forth all the surgeon's ingenuity and skill. The incision should be made directly over the tumour if one can be felt, and as in more than 50 per cent. of the cases intussusception starts at the ileo-caral valve an incision in the right linea semilunaris will usually expose it. If possible the tumour should be brought out through the abdominal wound. If this is impossible the fingers of one hand are to be passed along the distended bowel, and trace the intussusception downwards till its lower end is reached. The enclosed bowel is then to be gently forced upwards through the coats of the large colon and gradually reduced, while the other hand exercises gentle traction on the upper end. In reducible cases this is often fairly easy until the last inch or so is reached. This having been strangled longest is most œedematous and swollen, and much care and gentleness is often necessary in reducing this last piece to avoid tearing or otherwise damaging the bowel. The vermiform appendix generally appears when the reduction is nearly complete.

Nothing more should be done in an early case. The abdomen is to be quickly closed, and all means taken to counteract shock in so young a patient. The after-treatment is the same as that after reduction of a strangulated external hernia.

Unfortunately, when time has been lost in trying less effectual measures, or the case has not been seen or recognised until late, the intussusception when exposed will be found to be irreducible, and the imprisoned bowel sometimes gangrenous. The case is then truly a desperate one, and the utmost skill will rarely save the patient. The mode of treatment will depend greatly upon the patient's general condition.

The ideal method is certainly to excise the whole of the intussusception, and to unite the divided upper and lower ends of the intestine by one of the numerous methods of intestinal anastomosis. A Murphy's button, in my opinion, would be the best, as being the most speedy. Unfortunately the patient is but very rarely in a condition to stand so severe an operation.

Suocessful cases where this hastbeen done have been reported by Banks, Cripps, Pick, Lees, Silcock, and others, ${ }^{1}$ but the great majority of such cases have died from shock or peritonitis after the operation.

The other is to make an artificial anus above the intussusception, and later on to perform an intestinal anastomosis, or to leave Nature to separate the gangrenous bowel.

Mention should be made of a method proposed by Rydygier and carried out by him. It consists in suturing the entering piece of intestine to the ensheathing tube at its neck by a continuous suture, and then, opening the ensheathing tube, extracting the intussuscepted piece of bowel and excising it within the sheath. By this means less intestine is excised than in total resection of the intussusception, and the author claims that it is speedier than an ordinary intestinal anastomosis by suture. All these methods are indeed but desperate resources, and attended with a very high mortality, so high indeed, that it is questionable whether in cases where we know beforehand that the bowel must be gangrenous we should submit the patient to the extra shock of an operation, or leave him to the very slender chance of cure by spontaneous separation of the gangrenous bowel.

Case I.-Acute Ileo-c.ecal Intussusception: Abdominal Section REDUCTION : DEATH.

History; -J. L., a female infant of 7 months, was admitted into the Children's Hospital on June roth, r897, suffering from acute intussusception. The child bad been suddenly taken ill with abdominal pain, collapse, and vomiting thirty hours before admission. There had been several slight actions of the bowels, and small quantities of bloody mucus had been passed per anum. Vomiting continued up till admission.

Condition on Admission.-The child was somewhat collapsed, sunken, pulse 120 , temperature $97^{\circ}$. No tumour could be felt through the pous a distinct fulness to be felt in Douglas's pouch, and the examining finger on withdrawal was covered with blood-stained mucus.

Operation.-A diagnosis of acute intussusception was made, and abdominal section performed two hours after admission. A long mesial incision was made, and the intussusception felt for with two fingers of one hand. As it could not be found, the small intestines were brought out through the abdominal wound and traced downwards. A large intussusception was, after some difficulty, discovered in the true pelvis. It consisted of the lower part of the small intestine, which had become invaginated into the ascending. transverse, and descending colon, dragging them all into the pelvis. The intussusception was pushed back out of the descending and transverse colon without any trouble, but the reduction of the last few inches near the cæcum gave a good deal of trouble. It was found to have started at the ileo-ecal valve. After reduction, the walls of the small intestine and cæcum were found much thickened and odematous, and had much blood extravasated into them. The abdominal wound was then quickly closed, and the child put back to bed.

作 were opened several times, and a large quantity of blood passed with the motion. The the night of the third day the child suddenly became very collapsed, and, in spite of free stimulation, sank and died.

spite of free stimulation, sank and died. bid the Necropsy.-The post-mortem examination held the next day revealed
little. There was no peritonitis. The abdominal wound was sound. The lowest 6 inches of the ileum and cæcum were very much discoloured, and contained much extravasated blood in their walls. There was some lymph on their peritoneal coats.

Case ir.-Acute Ileo-cecal Intussusception: Abdominal Section: REDUCTION : RECOVERY

History.-J. J., a little boy aged 4, was admitted into the General Hospital on March 28 th, r898, with the history that at 9 A.M. that day he had been suddenly seized with violent abdominal pain. He became very collapsed and vomited almost continuously for an hour. He was then violently purged and passed a considerable quantity of blood per rectum. vomiting continued up till his admission to hospital at 3.30 P.M., but the collapse passed off. He had always been a delicate boy and suffered much from bronchitis.

Condition on Admission. -The temperature was $97^{\circ} \mathrm{F}$. The pulse $\mathrm{rr}$, small and regular. He wore an anxious expression and complained of abdominal pain across the umbilicus. The abdomen was lax, and there able tumour could be easily felt. It was tender on pressure and could be 
felt to harden when it was pressed. The rectum contained a little blood and mucus.

Operation.-An anæsthetic was given and laparotomy performed seven and a half hours after the onset of the symptoms. The opening was made in the right linea semilunaris, immediately over the tumour. The intussusception, which was five inches long, was brought outside the abdomen. which required considerable care. The ileo-cæcal valve formed the apex of the intussuscepted bowel. The abdomen was closed in the usual manner, the whole operation lasting only nineteen minutes.

After-history. - The patient's recovery was rapid and complete. For a few lays after the operation he had a good deal of bronchitis, aggravated
by his getting out of bed within a few hours of the operation. The bowels were opened naturally on the fourtl day and he passed a hard fæecal mass which was covered with blood. The stitches were removed on the eighth day, and he was discharged from the hospital early in May wearing a small abdominal belt to support the operation scar.

Case iII.-ACcte Ileo-c fCal Intussusception: ABdomjal Section:

REDUCTION : RECOVERY.
History:-A.T., a boy, aged 3 5ears, was admitted into the General Hospital, Birmingham, on March 29th (just twenty-four hours after the previous patient) suffering from abdominal pain and vomiting. At r P.M. on the day of admission, shortly after straining at the closet without any action of the bowels, he was seized with violent pain in the right side o the abdomen. He vomited several times during the afternoon, and had repeated attacks of abdominal colic. About an hour before admission he and the collapse passed off. He had previously been in good health, and the collapse passed off. He had previously been in good health, though the action of the bowels liad been promewhat ine

al in and regular. At times he lay apparently quite comfortable, and would attacks of colic, which produced a good deal of collapse. The abdominal walls were blistered and inflamed, the result of hot turpentine fomentations. In the intervals between the attacks of colic a small sausage-shaped tions. In the intervals between the attacks of colic a small sausage-shaped mass was not tender, and was freely movable. The rectum was empty. The bowels harl been opened once after the beginning of the illness.

opcration.-The diagnosis of intussusception being fairly clear, the patient was at once anestlietised, and laparotomy performed seven hours aiter the commencement of his symptoms. A $3^{\frac{1}{2}-i n c h ~ i n c i s i o n ~ w a s ~ m a d e ~ i n ~}$ the right linea semilunaris, and the tumour exposed. It was brought outside the abdomen with some difficulty. The tension on its mesentery in order to do this produced a good deal of shock, which passed off when it was relieved. The intussusception was an ileo-creal one, and measured $3 \frac{1}{2}$ inches. The invaginated bowel was easily reduced except for its last inch. This was swollen and redematous, and after reduction appeared as a raised codematous ring on the surface on the intestine. The abdo freel dusted with boracic acirl powder.

A/ter-history-Notwithstanding the raw state of the abdomen the wound healed by first intention, and the stitches were all removed on the eiglith day. The bowels were opened on the third day after the operation, and a hard blood-stained facal mass was passed. They were hoy was kept in bed a month to consolidate the operation scar. II was discharged well from the hospital on May rsth, and has remained in good health since.

Case IV.-Ileo-C.tcal Intessusception: Abdomisal Section :

History.-On September 2nd, 1898 . I saw W. M., with Dr. Gifford, of Brierley Hill. to whom I am indebted for the clinical notes of the case. He was a aelicate boy, aged 8 years, who had been inl for five days with acute abdomit two days previously. he was seized with diarrlcea and abdominal pain. Some castor oil was given to clear out the bowels, but the pain persisted. On August 3 oth he vomited twice, but got up, as he blood or mucus passed. On August 3 ist the diarrhea still continued, with rather more pain. An indefinite swelling could be felt in the with lather more pain. An indefinite swelling could be felt in the the diarrhœa still continued, and the mass in the iliac region extended upwards into the right loin. In the evening he became much worse, passing watery motions every hour or so, while the lumbar swelling rapidly increased in size. The temperature was $99.6^{\circ}$, and the pulse ro. The tumour had reached the right hypochondrium, and the boy's condition appeared desperate.

Abdominal Section.-At x P.M. on September 2 nd an incision was made in the right linea semilunaris over the tumour. An intussusception starting at the ileo-cæcal valve, and passing up the ascending colon into the transverse colon, was exposed. There was no peritonitis, but the colon was enormously distended by the intussuscepted bowel, its walls being purplish black in colour, extremely thin, and in one place apparently gangrenous. The intussusception was quite irreducible, and it was found quite impossible, owing to its size and fixity. to bring it outside the abdomen to deal with it. The walls of the colon were therefore united to the edges of the incision in the parietal peritoneum in the upper part of the wound, and an area of apparently gangrerous large intestine thus shut off from the abdominal cavity, as in an ordinary colotomy. The rest of the abdominal wound was closed in the usual way. After-history.-On recovering consciousness he was given a small morphine hypodermic injection and nourishment given entirely per rectum. His temperature that night was $98^{\circ}$, and pulse 140 . Some flatus was passed from
the gangrenous area in the colon. On September 3 rd it was noted that no more vomiting had occurred; he was given morphine for his extreme $r$ istlessness. He was passing flatus through the wound and per anum. 'he pulse was 160 , and the temperature $97.8^{\circ}$. He made a protracted con-
valescence. There was a good deal of cellulitis from the upper angle of the wound. Pus tracked across the abdomen and round the lett side of the body, and an abscess was eventually opened and sloughs removed from it on the left side of the spinal column. During all this time his pulse ranged from 125 to 165 , and his temperature was as high as $103.5^{\circ}$. He only vomited once or twice during convalescence. The bowels were opened regularly by enemata. They were liquid, but not offensive, and never contained any sloughs. The abdomen remained much distender flatus frequently passing through it, and a small fistula still persists through which a little black discharge occasionally finds its way. The emaciation during the first few weeks was alarming in spite of the large
quantities of fluid food taken. At the end of four weeks he was giverd
solid food, and then began to put on flesh again. He is at present apparsolid food, and then began to put on flesh again. He is at present apparently as well and active as ever, save for the slight discharge
fistula. The bowels act daily without any trouble or discomfort.

REFERENCES

1 British Medical Joursal, 1895, i, p. 410; Ibid., i, 777 ; Quart. Mcd. Jous. 1896. 7 , 107; Lancet, 1898, i, 1400.

\section{PERITONITIS AS A CAUSE OF INCREASED PERISTALSIS IN THE RECTUM AND IN OTHER PARTS OF THE INTESTINE:*}

By CHARLES W. CATHCART, F.R.C.S.,

Senior Assistant Surgeon, Royal Infirmary, Edinburgh.

WE are all so familiar with paralysis of the bowel in acute peritonitis, that we are apt to think that increased action of the bowel can hardly be due to the same cause acting under different circumstances. I for one did not realise it till the following case brought it home to me.

\section{Case i.-Pelvic Peritonitis.}

About five year's ago Dr. P. A. Young asked me to see with him, late ne night, a married woman, aged 37 , who showed certain obscure ab. dominal symptoms, and was in an anxious condition.

II istory of Attack.-About midday, while sitting in a tramway car, she had been suddenly scized with intense abdominal pain, and had only with the greatest difficulty dragged herself from wheye the car left her to the rooms in which she was living. Dr. Young saw the tep of her bed half undressed, faint and collapsed, and with : bedpan under her. Her bowels were being so frequently moved that she thought she had "dysentery." There was nothing in the bedpan, howerer, pulse roo, temperature normal. She had vomited several times, and complained of great pain, felt chiefly about the umbilicus, which came on ine severe paroxysms, with intervals of about two minutes. The abdomers was tender to touch. Various palliative measures were adopted, and when I saw her the pain was less, and the tenesmus had diminished. She had an anxious look, and was very nervous about herself. Pulse was then about ro8, temperature normal. The abdomen on inspection was not distended: respiratory movements impaired. The muscular wall was resistant all over, especially in the left iliac fossa, and there was a good deal of tenderness over the lower part of the abdominal wall. Per rectum. there seemed to be a little "ballooning," but nothing definitely abnormal The walls of the vagina seemed unduly hot, but that was all.

Previous Iristory.-She had been married for twenty years, and had two sons aged respectively 18 and ig. Shortly after the birth of the seconcis son she had had a miscarriage, but it did not seem to have left any ill effects, for her menstruation had gone on regularly at three weeks' intervals. It had usually lasted two or three days, and had caused no trouble. going upstairs, but Dr. Young had been unable to make out anything to going upstairs, but Dr. Young had been unable to make out anything to this sudden seizure she had been in bed with a sharp attack of follicular tonsillitis during the progress of a menstrual period. Althouglh recover.ing from this attack she had not felt well ; her tongue had been furred and her liver and stomach had been apparently out of order. On the morning on which she was taken ill her bowels had been moved several prescribed.

Diagnosis. - We found it very difficult to make up our minds about the case, but thought that fæcal impaction in the sigmoid flexure was a feasible and the most probable diagnosis. There was no reason for thinking that the pelvic organs had been diseased; and the region of the vermiform appendix did not seem involved. Un the other hand, colic from fæcal impaction sometimes causes great collapse, and although she said that her bowels had always been regular, and that they had moved clude the possible presence of fæcal masses. may set up irritation, and cause a loose catarrhal discharge which finds its way past them. There were certainly symptoms pointing to peritonitis, but in the absence of anything to explain its occurrence, and underto treat the case by palliative measures, and watch its further development.

After-history. - During the night the patient sent for Dr. Young on account of a feeling of irritation in the bladder. This was relieved after the use of the catheter, and next morning she did not complain of it. Her general condition in the morning seemed much the same, but her pulse was quicker-that is, irs, and her abdomen was more swollen and tender.
Throughout the day she grew weaker, and about 5.30 P.M. took a sudden * The substance of a pa yer read before the Medico-clinurgical society or Edinburgh, March ist, 1899. 